\title{
Extraskeletal Ewing's sarcoma of the thoracic epidural space: Case report and review of the literature
}

\author{
TAKETOSHI YASUDA ${ }^{1}$, KAYO SUZUKI $^{1}$, MASAHIKO KANAMORI $^{1,2}$, TAKESHI HORI $^{1}$, \\ DALI HUANG ${ }^{3}$, JULIA A. BRIDGE ${ }^{3-5}$ and TOMOATSU KIMURA ${ }^{1}$
}

\begin{abstract}
Departments of ${ }^{1}$ Orthopaedic Surgery and ${ }^{2}$ Human Science 1, University of Toyama, 2630 Sugitani, Toyama 930-0194, Japan; Departments of ${ }^{3}$ Pathology and Microbiology, ${ }^{4}$ Orthopaedic Surgery, and ${ }^{5}$ Pediatrics, University of Nebraska Medical Center, 983135 Nebraska Medical Center, Omaha, NE 68198-3135, USA
\end{abstract}

Received March 3, 2011; Accepted May 6, 2011

DOI: $10.3892 / o r .2011 .1326$

\begin{abstract}
The occurrence of primary extraskeletal Ewing's sarcoma (EES) of the spinal epidural space has been rarely reported in the literature. The clinical, radiologic and pathologic features of a case of EES occurring in the thoracic epidural space are presented. A 37-year-old woman presented with a one-year history of back pain. Magnetic resonance imaging demonstrated an epidural mass at the T8-9 level. Laminectomy and partial resection of the tumor were performed. The differential diagnosis of a spinal epidural mass is broad. Histopathological and molecular cytogenetic examinations confirmed an EES arising from the thoracic epidural space. Despite receiving both chemotherapy and radiotherapy, the patient died of respiratory insufficiency due to medulla oblongata metastasis 22 months after the initial consultation. Awareness of this entity will allow this rare diagnosis to be considered and facilitate appropriate management. A review of the literature on spinal epidural EES is also presented.
\end{abstract}

\section{Introduction}

Ewing's sarcoma is a malignant neoplasm of uncharacterized mesenchymal cell origin arising in the bones, rarely in soft tissues (1). Extraskeletal Ewing's sarcoma (EES), the extraosseous form of Ewing's sarcoma, was first described by Tefft et al in 1969 (2). The most common sites are the chest wall, paravertebral muscles, extremities, buttocks, and retroperitoneal space (3), but involvement of the epidural space is uncommon. To date, the number of reported cases of EES arising from the epidural space remains small $(2,4-23)$. An additional case of

Correspondence to: Dr Taketoshi Yasuda, Department of Orthopaedic Surgery, University of Toyama, Toyama 930-0194, Japan

E-mail: yasuda@med.u-toyama.ac.jp

Key words: diagnosis, extraskeletal Ewing's sarcoma, spinal epidural neoplasm epidural EES is reported, and the literature on epidural EES is reviewed.

\section{Case report}

A 37-year-old woman had a one-year history of back pain. She underwent a checkup in another hospital in October 2006. Magnetic resonance imaging (MRI) showed a wellcircumscribed, posterior epidural tumor compressing the spinal cord and extending from $\mathrm{T} 8$ to $\mathrm{T} 9$ with foraminal widening (Fig. 1A and B). Bone change was not shown by computed tomogram (CT) (Fig. 2). Laminectomy at T8-T9 and partial resection of the tumor were performed. Tumor cells showed uniform small round nuclei containing fine chromatin, scanty eosinophilic cytoplasm, and an indistinct cytoplasmic membrane. The initial clinicohistopathologic impression was atypical meningioma (Fig. 3).

However, the patient developed progressively increasing back pain and gait disturbance in May 2007. MRI showed a recurrent tumor from $\mathrm{T} 8$ to $\mathrm{T} 9$. Chest radiogram and $\mathrm{CT}$ showed no evidence of lung tumor. Since her paraplegia had progressed rapidly, partial resection of the tumor was performed again in June 2007. Histopathological study of the specimens revealed small round cell sarcoma arising from the epidural space (Fig. 4). Proliferation of small, variable, round or polygonal cells with hyperchromatic nuclei and scant cytoplasm was seen. Immunohistochemically, the tumor cells were positive for CD99 and neuron-specific enolase (NSE) and negative for leukocyte common antigen (LCA) and cytokeratins. Based on the histological features and the immunostain results, a diagnosis of EES was favored, and the specimen was submitted for molecular cytogenetic analysis. Fluorescence in situ hybridization (FISH) analysis was performed to assess the EWS gene locus. Following molecular diagnostic confirmation, the patient was given multiagent chemotherapy with vincristine, doxorubicin, cyclophosphamide, ifosfamide, and etoposide (VadCA-I/E) (24). She completed five cycles of chemotherapy, and the tumor showed significant shrinkage. However, 10 months later, a recurrent tumor and intramedullary dissemination were recognized. Partial resection of the tumor was performed again in May 2008. This was followed by radiotherapy of the total cervical and thoracic spine to a dose 

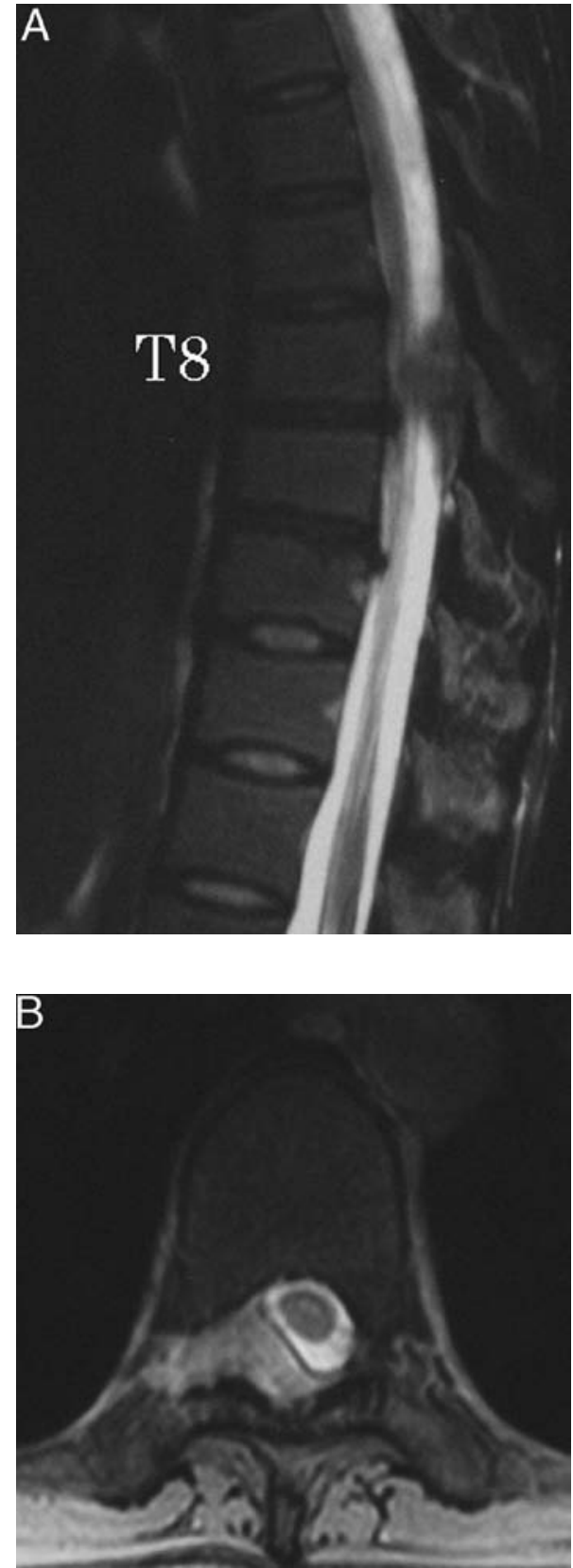

Figure 1. MRI findings at the initial consultation. (A) T2-weighted sagitta imaging, (B) T2-weighted axial imaging. MRI shows a circumscribed, posterior epidural tumor at the T8-9 level that is hyperintense to muscle. The tumor is compressing the spinal cord and extending from T8 to T9, with foraminal widening.

of 45 Gy over 5 weeks. However, the patient died of respiratory insufficiency due to medulla oblongata metastasis 22 months after the initial consultation.

FISH analysis. FISH studies of the first specimen were performed on a formalin-fixed, paraffin-embedded tissue section using the Ewing's sarcoma breakpoint region 1 (EWSR1), dual-color, break-apart probe (Vysis, Downer's Grove, IL, USA), which spans the known common breakpoints in the EWS gene on chromosome 22q12, as described previously $(25,26)$. Signals were enumerated in 100 nuclei from an invasive area of the tumor located by comparison with hematoxylin and eosin staining. Hybridization signals were

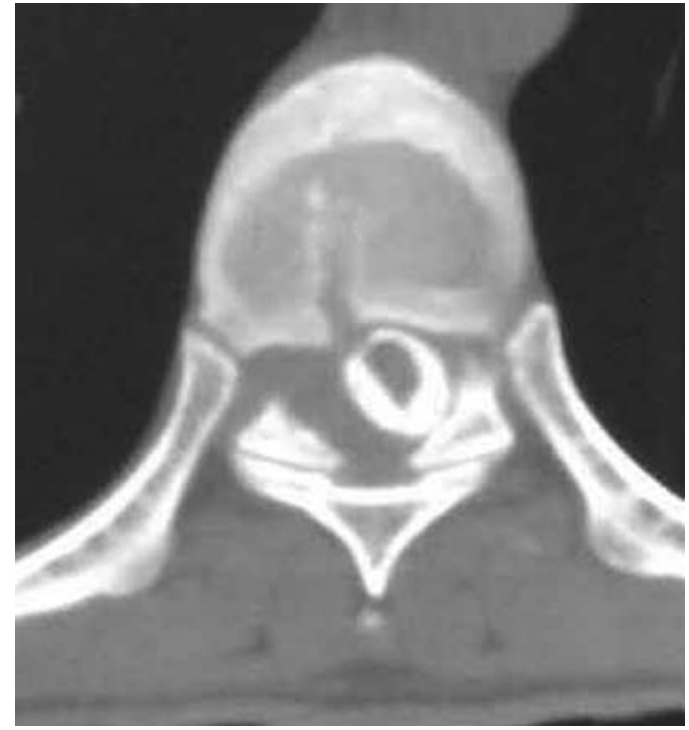

Figure 2. CT myelogram findings. The dura is compressed from the posterolateral side by the epidural mass. Bone change is not obvious.

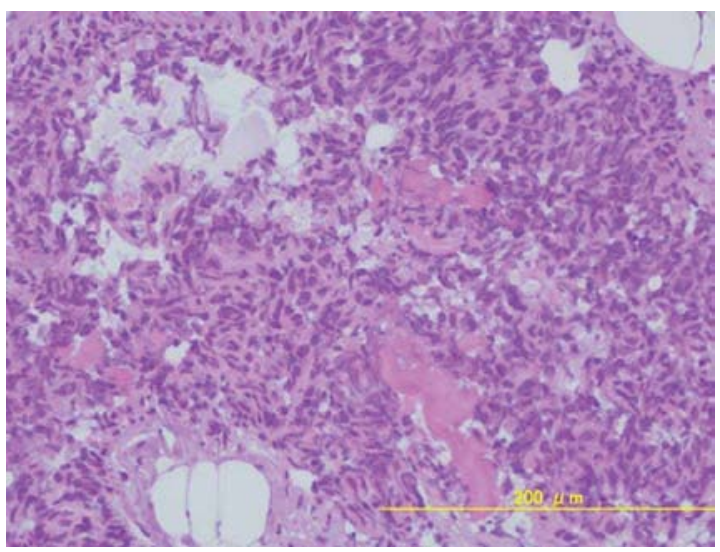

Figure 3. Histological appearance of the first surgical specimen. Tumor cells show uniform small round nuclei containing fine chromatin, scanty eosinophilic cytoplasm, and an indistinct cytoplasmic membrane. The initial clinicohistopathologic impression is atypical meningioma (hematoxylin and eosin stain, Scale bar: $200 \mu \mathrm{m}$ ).

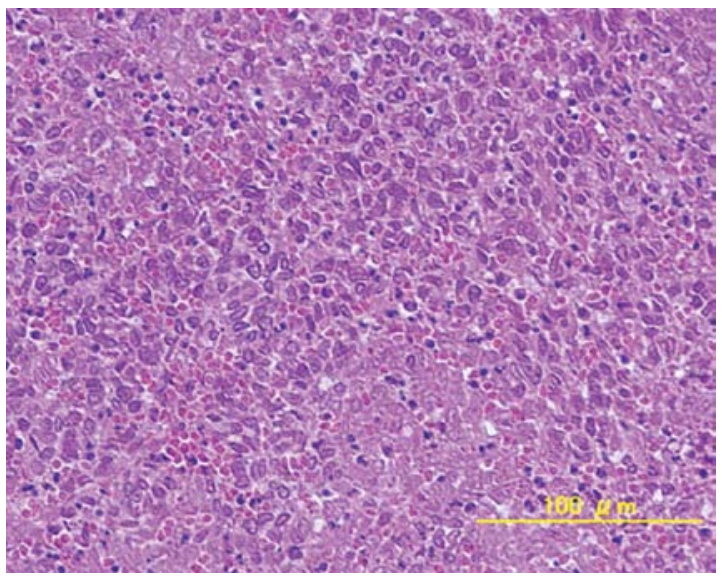

Figure 4. Histological appearance of the second surgical specimen. Diffuse proliferation of small, uniform round cells with hyperchromatic nuclei and scant cytoplasm is observed (hematoxylin and eosin stain, Scale bar: $100 \mu \mathrm{m})$. 
Table I. Reported cases of primary spinal epidural extraskeletal Ewing's sarcoma.

\begin{tabular}{|c|c|c|c|c|c|}
\hline $\begin{array}{l}\text { Case } \\
\text { (Ref.) }\end{array}$ & $\begin{array}{c}\text { Age (years)/ } \\
\text { Gender }\end{array}$ & Level & Resection & $\begin{array}{l}\text { Adjuvant } \\
\text { Treatment }\end{array}$ & $\begin{array}{l}\text { Outcome } \\
\text { (months) }\end{array}$ \\
\hline $1(2)$ & $6 / F$ & $\mathrm{~L} 4$ & Partial & CT, RT & DOD (48) \\
\hline $2(4)$ & $17 / \mathrm{M}$ & $\mathrm{S} 1-2$ & N/A & None & DOD (1) \\
\hline $3(4)$ & 20/M & $\mathrm{T} 2-5$ & Partial & CT, RT & DOD (13) \\
\hline $4(4)$ & $18 / \mathrm{F}$ & L5 & N/A & CT, RT & DOD (7) \\
\hline $5(5)$ & $18 / \mathrm{M}$ & L1 & Complete & CT, RT & NED (16) \\
\hline $6(5)$ & $27 / F$ & T6 & Complete & CT, RT & NED (120) \\
\hline $7(6)$ & 23/M & L5-S1 & Partial & CT, RT & DOD (12) \\
\hline $8(7)$ & $19 / \mathrm{M}$ & L2-3 & Partial & CT, RT & NED (6) \\
\hline $9(8)$ & $12 / \mathrm{M}$ & L3 & N/A & CT, RT & NED (15) \\
\hline $10(9)$ & $10 / \mathrm{M}$ & L4-S2 & Partial & CT, RT & DOD (16) \\
\hline $11(10)$ & $17 / \mathrm{M}$ & L3 & Partial & CT, RT & DOD (8) \\
\hline $12(11)$ & $18 / \mathrm{M}$ & $\mathrm{T} 11$ & Partial & CT, RT & DOD (42) \\
\hline $13(12)$ & $4 / \mathrm{M}$ & L1 & Complete & None & DOD (5) \\
\hline $14(13)$ & $7 / \mathrm{M}$ & T12-L1 & Partial & CT & NED (40) \\
\hline 15 (14) & $15 / \mathrm{F}$ & T12-L3 & N/A & N/A & N/A \\
\hline $16(15)$ & $22 / \mathrm{F}$ & C7-T1 & Partial & CT & NED (48) \\
\hline $17(15)$ & 38/M & $\mathrm{C} 5-7$ & Partial & $\mathrm{CT}$ & AWD (5) \\
\hline $18(16)$ & $24 / \mathrm{M}$ & $\mathrm{C} 1-5$ & Partial & $\mathrm{CT}, \mathrm{RT}$ & NED (25) \\
\hline 19 (17) & $29 / \mathrm{F}$ & $\mathrm{C} 3-5$ & Partial & CT, RT & NED (30) \\
\hline $20(17)$ & $18 / \mathrm{M}$ & $\mathrm{T} 8$ & Partial & CT, RT & AWD (18) \\
\hline $21(17)$ & $22 / \mathrm{M}$ & L5-S1 & Partial & CT, RT & NED (15) \\
\hline $22(17)$ & $31 / \mathrm{M}$ & L3-4 & Partial & CT, RT & NED (32) \\
\hline $23(17)$ & $13 / \mathrm{M}$ & $\mathrm{C} 3-5$ & Partial & CT, RT & NED (11) \\
\hline $24(18)$ & $33 / \mathrm{M}$ & T4-7 & Complete & CT, RT & NED (3) \\
\hline 25 (19) & $12 / \mathrm{F}$ & $\mathrm{T} 1-3$ & Partial & CT (PBSCT), RT & DOD (32) \\
\hline $26(20)$ & $7 / \mathrm{F}$ & $\mathrm{C} 2-4$ & Complete & CT (PBSCT), RT & NED (60) \\
\hline $27(21)$ & $15 / \mathrm{F}$ & $\mathrm{C} 3-7$ & Partial & N/A & N/A \\
\hline $28(22)$ & $13 / \mathrm{M}$ & $\mathrm{T} 9$ & Partial & CT, RT & AWD (9) \\
\hline $29(23)$ & $18 / \mathrm{M}$ & C6-T1 & Complete & $\mathrm{CT}$ & NED (13) \\
\hline 30 (this case) & $37 / \mathrm{F}$ & T8-9 & Partial & CT, RT & DOD (22) \\
\hline
\end{tabular}

M, male; F, female; $\mathrm{C}$, cervical; T, thoracic; L, lumbar; CT, chemotherapy; RT, radiotherapy; PBSCT, peripheral blood stem cell transplantation; DOD, dead of disease; NED, no evidence of disease; AWD, alive with disease; N/A, not available.

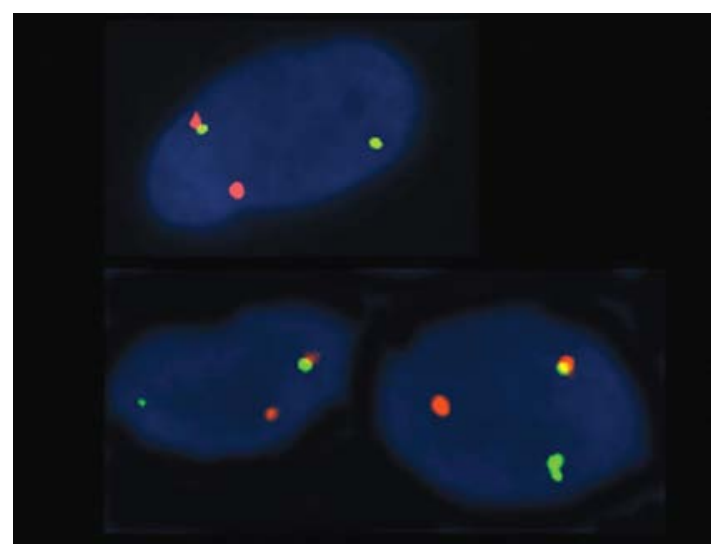

Figure 5. FISH analysis with the EWSR1 breakpoint flanking probe set (proximal portion, orange; distal portion, green) shows splitting of the orange and green signals, indicating disruption of EWS. assessed in 200 interphase nuclei with strong, well-delineated signals by two different individuals. Tumor samples showed break-apart signals in 83 and $93 \%$ of cells, respectively (Fig. 5).

\section{Discussion}

Ewing's sarcomas arising from soft tissues are referred to as EES. Most EES patients are between 10 and 30 years of age, with a peak incidence at $\sim 20$ years of age (3). The most common sites are the chest wall, extremities, buttocks, and retroperitoneal space. However, a number of cases have been reported to arise in various locations, such as the small intestine, vagina, kidney, skin, larynx, esophagus, and paravertebral region (3). Only 30 cases of EES arising in the spinal epidural space, including our case, have been reported in the English literature (Table I). The mean age at presentation was 18.8 years (range: $4-38$ years), 
with $73 \%$ of the patients being between 10 and 20 years old. Male patients predominated $(66 \%)$. The male-female ratio of 1.5:1 in spinal epidural EES resembles that in Ewing's sarcoma of bone.

MRI is the most useful tool for early diagnosis to determine the extent of the tumor. The differential diagnosis of a spinal epidural mass is broad. Most epidural masses are metastatic malignancies associated with lung cancer, breast cancer, and lymphoma (13). Although primary epidural tumors are rare, primary epidural masses include schwannoma, meningioma, and primary bone tumor. Schwannoma was ruled out due to the lack of an intradural lesion. Meningioma was considered a distinct possibility. Epidural EES is particularly unusual, and it was not initially considered in the differential diagnosis. There are 10 cases documenting the MRI features of EES (14-18,20-23), with a limited case series, and they showed so-called dumbbell-shaped tumors that extended from an intraspinal origin with foraminal widening. In three cases, scalloping of bone was seen $(15,23)$. The present case showed a dumbbell-type tumor without bone change.

Histopathologically, EES is classed as a small round cell tumor because of the uniform small round cell microscopic appearance. Such small round cell tumors may be misdiagnosed as lymphoma, small cell metastatic carcinoma from lung, and poorly differentiated synovial sarcoma. Therefore, immunohistochemical analysis is needed for further tumor classification. Approximately $95 \%$ of EESs show membranous immunoreactivity for CD99 (MIC2), but this is not specific $(27,28)$. Most lymphomas are positive for LCA. Since only $\sim 50 \%$ of poorly differentiated synovial sarcomas express cytokeratins, and many show CD99 immunoreactivity, the immunohistochemical differentiation of poorly differentiated synovial sarcoma from EES is difficult in some cases (3). Finally, this case was diagnosed as EES based on identifying, in the majority of aberrant interphase cells examined, the presence of a rearranged $E W S$ gene locus. The $\mathrm{t}(11 ; 22)(\mathrm{q} 24 ; \mathrm{q} 12)$ translocation, a chromosomal abnormality specific to the Ewing's sarcoma, is detected in $\sim 90 \%$ of cases (29). This translocation results in the formation of the EWS-FLII fusion gene (30). Another $10 \%$ of cases have a variant translocation fusing EWS to closely related EWS genes such as ERG, ETV1, EIAF, and $F E V$. The ability to identify tumor-specific chromosomal translocations and associated fusion gene transcripts using interphase reverse transcriptase-polymerase chain reaction (RT-PCR) $(29,31,32)$ and FISH $(26,32)$ can be useful. In the present case, limited paraffin-embedded material from a resected specimen was available for FISH studies, and epidural EES was diagnosed.

The results of treatment for epidural EES are very poor, even if both chemotherapy and radiotherapy are given. To date, the 5-year survival rate of EES has been reported as being between $38 \%$ (33) and $67 \%$ (34). However, the 5-year survival rate in EES around the spinal canal was reported to be between 0 and $37.5 \%$ (13) (Table I). Of 28 cases for whom follow-up data were available, 11 cases died after an average of 19 months, and 17 cases lived for an average of 27 months (range: 3-120 months). A diagnosis of EES tends to be late due to its rarity and the tumor being found after becoming massive (19). Furthermore, 20 of 26 cases (77\%) were only partially resected due to infiltration of the surrounding nerve tissues.
Ten of these cases died after an average of 20 months. Five of the six cases that were completely resected lived an average of 42 months. Therefore, the poor prognosis of epidural EES may result from the diagnostic difficulty and the high rate of only partial resection of the tumors.

In conclusion, a rare case of epidural EES without evidence of systemic disease or chronic illness was reported. Imaging features may not distinguish it from other tumors, such as metastatic tumor or lymphoma. Some form of biopsy or partial resection was needed in all reported cases to confirm the diagnosis allowing appropriate management.

\section{References}

1. Ushigome S, Machinami R and Sorensen PH: Ewing sarcoma/ Primitive neuroectodermal tumour. In: WHO Classification of Tumours, Pathology and Genetics of Tumours of Soft Tissue and Bone. Fletcher CDM, Unni KK and Mertens F (eds). IARC Press, Lyon, pp297-300, 2002.

2. Tefft M, Vawter GF and Mitus A: Paravertebral 'round cell' tumors in children. Radiology 92: 1501-1509, 1969.

3. Weiss SW and Goldblum JR: Extraskeletal Ewing's sarcoma/ primitive neuroectodermal tumor family. In: Enzinger and Weiss's Soft Tissue Tumors. Weiss SW, Goldblum JR (ed). 5th edition, Mosby, St. Louis, MO, pp963-979, 2007.

4. Angervall L and Enzinger FM: Extraskeletal neoplasm resembling Ewing's sarcoma. Cancer 36: 240-251, 1975.

5. Scheithauer BW and Egbert BM: Ewing's sarcoma of the spinal epidural space: report of two cases. J Neurol Neurosurg Psychiatry 41: 1031-1035, 1978.

6. Mahoney JP, Ballinger WE Jr and Alexander RW: So-called extraskeletal Ewing's sarcoma. Report of a case with ultrastructural analysis. Am J Clin Pathol 70: 926-931, 1978.

7. Fink LH and Meriwether MW: Primary epidural Ewing's sarcoma presenting as a lumbar disc protrusion. J Neurosurg 51: 120-123, 1979

8. Simonati A, Vio M, Iannucci AM, Bricolo A and Rizzuto N: Lumbar epidural Ewing sarcoma. Light and electron microscopic investigation. J Neurol 225: 67-72, 1981.

9. Spaziante R, de Divitiis E, Giamundo A, Gambardella A and Di Prisco B: Ewing's sarcoma arising primarily in the spinal epidural space: fifth case report. Neurosurgery 12: 337-341, 1983.

10. Ruelle A and Boccardo M: Primary extra-skeletal Ewing's sarcoma mimicking a disc protrusion. Neurochirurgia (Stuttg) 30: 125-126, 1987.

11. Sharma BS, Khosla VK and Banerjee AK: Primary spinal epidural Ewing's sarcoma. Clin Neurol Neurosurg 88: 299-302, 1986.

12. Machin Valtueña M, Garcia-Sagredo JM, Muñoz Villa A, Lozano Giménez C and Aparicio Meix JM: 18q-syndrome and extraskeletal Ewing's sarcoma. J Med Gene 24: 426-428, 1987.

13. Kaspers GJ, Kamphorst W, von de Graaf M, van Alphen HA and Veerman AJ: Primary spinal epidural extraosseous Ewing sarcoma. Cancer 68: 648-654, 1991.

14. Allam K and Sze G: MR of primary extraosseous Ewing sarcoma. Am J Neuroradiol 15: 305-307, 1994.

15. Shin JH, Lee HK, Rhim SC, Cho KJ, Choi CG and Suh DC: Spinal epidural extraskeletal Ewing sarcoma: MR findings in two cases. Am J Neuroradiol 22: 795-798, 2001.

16. Kennedy JG, Eustace S, Caulfield R, Fennelly DJ, Hurson B and O'Rourke KS: Extraskeletal Ewing's sarcoma: a case report and review of the literature. Spine 25: 1996-1999, 2000.

17. Mukhopadhyay P, Gairola M, Sharma M, Thulkar S, Julka P and Rath G: Primary spinal epidural extraosseous Ewing's sarcoma: report of five cases and literature review. Australas Radiol 45: 372-379, 2001.

18. Gandhi D, Goyal M, Belanger E, Modha A, Wolffe J and Miller W: Primary epidural Ewing's sarcoma: case report and review of literature. Can Assoc Radiol J 54: 109-113, 2003.

19. Harimaya K, Oda Y, Matsuda S, Tanaka K, Chuman H and Iwamoto Y: Primitive neuroectodermal tumor and extraskeletal Ewing sarcoma arising primarily around the spinal column: report of four cases and a review of the literature. Spine 28: 408-412, 2003 
20. Kogawa M, Asazuma T, Iso K, et al: Primary cervical spinal epidural Extra-osseous Ewing's sarcoma. Acta Neurochir (Wien) 146: 1051-1053, 2004.

21. Siami-Namini K, Shuey-Drake R, Wilson D, Francel P, Perry A and Fung KM: A 15 -year-old female with progressive myelopathy. Brain Pathol 15: 265-267, 2005.

22. Athanassiadou F, Tragiannidis A, Kourti M, et al: Spinal epidural extraskeletal Ewing sarcoma in an adolescent boy: a case report. Pediatr Hematol Oncol 23: 263-267, 2006.

23. Ozturk E, Mutlu H, Sonmez G, Vardar Aker F, Cinar Basekim C and Kizilkaya E: Spinal epidural extraskeletal Ewing sarcoma. J Neuroradiol 34: 63-67, 2007.

24. Grier HE, Krailo MD, Tarbell NJ, et al: Addition of ifosfamide and etoposide to standard chemotherapy for Ewing's sarcoma and primitive neuroectodermal tumor of bone. N Engl J Med 348: 694-701, 2003.

25. Mazur MA, Gururangan S and Bridge JA: Intracranial Ewing sarcoma. Pediatr Blood Cancer 45: 850-856, 2005.

26. Yamaguchi U, Hasegawa $\mathrm{T}$, Morimoto $\mathrm{Y}$, et al: A practical approach to the clinical diagnosis of Ewing's sarcoma/primitive neuroectodermal tumour and other small round cell tumours sharing EWS rearrangement using new fluorescence in situ hybridization probes for EWSR1 on formalin fixed, paraffin wax embedded tissue. J Clin Pathol 58: 1051-1056, 2005.

27. Folpe AL, Goldblum JR, Rubin BP, et al: Morphologic and immunophenotypic diversity in Ewing family tumors: a study of 66 genetically confirmed cases. Am J Surg Pathol 29: 1025-1033, 2005
28. Ambros IM, Ambros PF, Strehl S, Kovar H, Gadner H and Salzer-Kuntschik M: MIC2 is a specific marker for Ewing's sarcoma and peripheral primitive neuroectodermal tumors. Evidence for a common histogenesis of Ewing's sarcoma and peripheral primitive neuroectodermal tumors from MIC2 expression and specific chromosome aberration. Cancer 67: 1886-1893, 1991.

29. Delattre O, Zucman J, Plougastel B, et al: Gene fusion with an ETS DNA-binding domain caused by chromosome translocation in human tumours. Nature 359: 162-165, 1992.

30. Janknecht R: EWS-ETS oncoproteins. The linchpins of Ewing tumors. Gene 363: 1-14, 2005.

31. Delattre O, Zucman J, Melot T, et al: The Ewing family of tumors: a subgroup of small round cell tumors defined by specific chimeric transcripts. N Engl J Med 331: 294-299, 1994.

32. Downing JR, Head DR, Parham DM, et al: Detection of the $\mathrm{t}(11 ; 22)(\mathrm{q} 24-\mathrm{q} 12)$ translocation of Ewing's sarcoma and peripheral neuroectodermal tumor by reverse transcription polymerase chain reaction. Am J Pathol 143: 1294-1300, 1993.

33. Shimada H, Newton WA Jr, Soule EH, Qualman SJ, Aoyama C and Maurer HM: Pathological features of extraosseous Ewing's sarcoma: a report from the intergroup rhabdomyosarcoma study. Hum Pathol 19: 442-453, 1988

34. Rud NP, Reiman HM, Pritchard DJ, Frassica FJ and Smithson WA: Extraosseous Ewing's sarcoma: a study of 42 cases. Cancer 64: 1548-1553, 1989. 